\title{
Comparing Health Status and Lifestyle in Chinese College Students
}

\author{
Xuelian Wang, Yoshio Sugiyama \\ Faculty of Human-Environment Studies, Kyushu University, Japan \\ Email: xuelian1984322@yahoo.co.jp
}

Received 14 October 2015; accepted 27 November 2015; published 30 November 2015

Copyright (C) 2015 by authors and Scientific Research Publishing Inc.

This work is licensed under the Creative Commons Attribution International License (CC BY). http://creativecommons.org/licenses/by/4.0/

c) (i) Open Access

\begin{abstract}
The study aimed to compare health status and lifestyle in university students. The participants were college freshmen from physical education majors $(N=195$, Mean $=20.9, S D=1.87)$ and the school of Urban and Environmental majors $(N=195$, Mean $=21.73, S D=0.93)$ in Dalian, China. The Diagnostic Inventory of Health and Life habit (DIHAL.2) scale (Tokunaga, 2003) was administered to all participants. A one-way sample t-test was used to analyze the difference in both interdepartmental and gender effects. Results of t-test indicated that there were significantly difference in physical health, social health and life habit. Moreover, students majoring in physical education were scored lower on the mental health domain compared to the physical and social health domains. The practical implication of this study focused on finding the difference between the students who regularly exercised and those who did not, and considered the characteristics of gender. Finally, we hope that this study would be available for physical education in university.
\end{abstract}

\section{Keywords}

Health Status, Lifestyle, Physical Education, College Students

\section{Introduction}

Recently, while China' economy is growing at a dramatic rate, young people are having trouble getting a job. Therefore, it is recommended that university students should study regularly. They take quite a while to study major course and English test which are conditions for graduating from university and will help them gain an upper hand for commence employment. On the other hand, they have little time to exercise. Although students' awareness regarding the benefits to exercise increased, they reported poor health and not getting enough exercise. Recent research at a Chinese university showed that over $60 \%$ of university students though they did not exercise enough and nearly 20\% of them were dissatisfied with their health (Wang \& Sugiyama, 2014). 
The WHO (2009) defines health as "a state of complete physical, mental and social well-being and not merely the absence of disease or infirmity". In China, there has recently been an increase focus on the health status of university students. Traditional Chinese health beliefs and the health education policy of the Chinese government have been reviewed. The current health status and lifestyle of university students in China was discussed, and the necessity for implementing physical education programs in universities to improve university students' health and lifestyle was emphasized (Wang \& Sugiyama, 2011). On the other hand, researchers in the field of sports psychology reached an agreement that engaging in sports could improve physical health (Ma, Yang, \& Wang, 2009; Mao, 2009; Wang, 2009). However they paid little attention to social health and mental health, which also contributes to health status. In China, there is no scale that evaluates health status and lifestyle. However, in Japan, Tokunaga \& Hashimoto (2001) developed an evaluation scale called Diagnostic Inventory of Health and Life Habit (DIHAL.2), which included the health level and life habit of individuals.

Physical education lesson was widely-regarded as a way to improve health and adjust smoothly to social situations (Wang, 2001). Previous studies show that university students who are physically active have better health status and lifestyle compared to those who are not active (Kiuchi, Arai, Urai, \& Nakamura, 2009). If exercise becomes a habit, it may improve dietary habit, rest habit and health status (Tokunaga \& Hashimoto, 2002).

We used DIHAL.2 in our study to compare the university students from physical education course to those from other majors. We hypothesize that students who are physically active will have a better health status and lifestyle than students who are physically inactive. We hope that our study results will contribute to the field of physical education.

\section{Method}

\subsection{Participants and Procedure}

One hundred ninety-five students (95 male and 100 female) from a physical education program (PE), and one hundred ninety-five students (81 male and 114 female) from the School of Urban and Environmental Science (UE) participated in the study. The study was approved by a university in Dalian, China. All of participants were college freshmen. They were given explanation for examination and each participant provided informed consent before the course began. Physical education is a required course in this university.

\subsection{Measurements}

We used Diagnostic Inventory of Health and Life habit (DIHAL.2) scale (Tokunaga, 2003). We translated it to a Chinese version. The technique of back-translation was employed. (Wang \& Sugiyama, 2014) tested the validity and reliability of scale for Chinese students. We examined the validity of the factors for four indices. The root mean square error of approximating (RMSEA) had a minimum of 0.045, the GFI index had a fit of 0.935 and AGFI index was 0.901. Each index indicated a good fit. This scale has 47 items under four categories (health status, exercise habits, dietary habits and rest habits). Furthermore, health status is divided into three subcategories (physical health, mental health and social health) and scores range from 12 to 60 points. There are 8 items on exercise habits (scores range from 8 to 40), 13 items on dietary habits (scores range from 13 to 65 points), and 14 items on rest habits (scores range from 14 to 70). All items answered on a 5-point Likert-type scale.

\subsection{Date Analysis}

One-way sample t-test was used to compare difference in health status and lifestyle between male and female students with the same major. We tested the difference between two majors by one-way sample t-test. The date analysis was performed using SPSS Version 12.0 for Windows.

\section{Results}

\subsection{The Comparison for Gender in the Same Major}

A t-test was performed to assess the difference in health status and lifestyle for gender in the same major (Table 1). The results indicated that men with a PE major had significantly higher scores than women with a PE major on physical health, social health, exercise habit, Dietary habit and rest habit. On other hand, women were significantly lower than men were in mental health. When a UE major, women were significantly higher than men 
Table 1. One-way sample $t$-test on health status and lifestyle in the same department.

\begin{tabular}{|c|c|c|c|c|c|c|}
\hline & \multicolumn{2}{|c|}{$\mathrm{PE}$} & \multirow{3}{*}{$t$} & \multicolumn{2}{|c|}{$\mathrm{CH}$} & \multirow{3}{*}{$t$} \\
\hline & \multicolumn{2}{|c|}{$\mathrm{M} \pm \mathrm{SD}$} & & \multicolumn{2}{|c|}{$\mathrm{M} \pm \mathrm{SD}$} & \\
\hline & male (95) & female (100) & & male (81) & female (114) & \\
\hline Physical Health (1) & $16.65 \pm 2.78$ & $15.27 \pm 2.91$ & $3.39^{* *}$ & $14.47 \pm 2.90$ & $14.49 \pm 2.54$ & 0.06 \\
\hline Mental Health (2) & $8.32 \pm 3.38$ & $10.65 \pm 3.61$ & $4.65^{* *}$ & $10.95 \pm 3.09$ & $13.20 \pm 2.67$ & $5.44^{* *}$ \\
\hline Social Health (3) & $17.06 \pm 2.71$ & $15.90 \pm 2.93$ & $2.87^{* *}$ & $14.62 \pm 3.04$ & $14.10 \pm 2.56$ & 1.30 \\
\hline Health Status (1) - (3) & $42.03 \pm 4.49$ & $41.82 \pm 5.31$ & $3.30^{* *}$ & $40.04 \pm 4.60$ & $41.79 \pm 4.89$ & $2.53^{*}$ \\
\hline Exercise Habit (4) & $34.29 \pm 4.41$ & $32.95 \pm 4.34$ & $2.15^{*}$ & $29.73 \pm 4.85$ & $28.13 \pm 5.25$ & $2.16^{*}$ \\
\hline Dietary Habit (5) & $52.26 \pm 6.57$ & $49.88 \pm 8.67$ & $2.16^{*}$ & $47.77 \pm 6.32$ & $49.07 \pm 6.08$ & 1.45 \\
\hline Rest Habit (6) & $55.64 \pm 7.95$ & $52.06 \pm 8.29$ & $3.08^{* *}$ & $50.37 \pm 6.89$ & $49.54 \pm 6.77$ & 0.84 \\
\hline Life Habit (4) - (6) & $142.20 \pm 17.68$ & $134.89 \pm 18.17$ & $2.85^{* *}$ & $127.86 \pm 16.01$ & $126.74 \pm 15.67$ & 0.49 \\
\hline
\end{tabular}

were in mental health. Men were significantly higher than women in exercise habit. There were no significantly differences in physical health, social health, dietary habit and rest habit for students in UE major.

\subsection{The Comparison between PE Major and UE Major}

Table 2 summarizes the difference between two majors. The results of a t-test showed that men with a PE major had significantly higher scores than UE major in physical and social health. However, men in a UE major were significantly higher than the men who come from PE major in mental health. Men in a PE major scored significantly higher than UE major in exercise habit, dietary habit and rest habit. When we compared date for women, we noted the results were same as men on health status and lifestyle but not for dietary habit, which had no significantly difference.

\section{Discussion}

In this study, we aim to observe the difference in health status and lifestyle between a person who is physically active and physically inactive. Therefore, we chose subjects From a PE major who regularly exercise and a UE major who are usually sedentary. According to the results, it should be noted that women had significantly higher scores than men on mental health regardless of the major. It indicated than men got nervous easier, and women adapt successfully to group life. This is in agreement with Li \& Wang (2007). However, in Japan, Tokunaga \& Hashimoto (2001) performed research on health status and lifestyle. They reported that there was insignificantly difference in gender. In PE major, men scored significantly better than women did in physical health status, social health and lifestyle. We found that men were likely to do sports than women; women were shorter on physical strength than men were, and men participate more eagerly in community activities and events than women did. In their personal life, men have better regular fitness habits, pay more attention to nutritional balance, and have much more sleeping time than women do. On the other hand, in EU majors, just mental health and exercise habit showed significantly difference by gender. Results demonstrated that men had greater awareness regarding the benefits of exercise compared to women.

In the interdepartmental comparison, both men and women that were PE majors had better physical health, social health and life habit than UE majors. Thus, we propose a hypothesis that regular exercise habits are critically useful for health status. Tokunaga \& Hashimoto (2002) reported that physical activity, eating habit, relaxation and sleeping were all related to health.

While we found an interesting result that UE majors were better than PE majors in both sexes on mental health. It was clear that the students in the UE major adjusted easier to being group. Our result was different from the research of Sato, Saito, \& Kamioka (1996). The students with a PE major were also quickly to impatience. We cannot explain it clearly, thus it is an issue for future research in Chinese students. 
Table 2. One-way sample $t$-test on health status and lifestyle according to department.

\begin{tabular}{|c|c|c|c|c|c|c|}
\hline & \multicolumn{2}{|c|}{ Male } & \multirow{3}{*}{$t$} & \multicolumn{2}{|c|}{ Female } & \multirow{3}{*}{$t$} \\
\hline & \multicolumn{2}{|c|}{$\mathrm{M} \pm \mathrm{SD}$} & & \multicolumn{2}{|c|}{$\mathrm{M} \pm \mathrm{SD}$} & \\
\hline & PE (95) & UE (81) & & PE (100) & UE (114) & \\
\hline Physical Health (1) & $16.65 \pm 2.78$ & $14.47 \pm 2.90$ & $5.09^{* *}$ & $15.27 \pm 2.91$ & $14.49 \pm 2.54$ & $2.09^{*}$ \\
\hline Mental Health (2) & $8.32 \pm 3.38$ & $10.95 \pm 3.09$ & $5.36^{* *}$ & $10.65 \pm 3.61$ & $13.20 \pm 2.67$ & $5.93^{* *}$ \\
\hline Social Health (3) & $17.06 \pm 2.71$ & $14.62 \pm 3.04$ & $5.64^{* *}$ & $15.90 \pm 2.93$ & $14.10 \pm 2.56$ & $4.81^{* *}$ \\
\hline Health Status (1) - (3) & $42.03 \pm 4.49$ & $40.04 \pm 4.60$ & $2.91^{* *}$ & $41.82 \pm 5.31$ & $41.79 \pm 4.89$ & 0.04 \\
\hline Exercise Habit (4) & $34.29 \pm 4.41$ & $29.73 \pm 4.85$ & $6.54^{* *}$ & $32.95 \pm 4.34$ & $28.13 \pm 5.25$ & $7.26^{* *}$ \\
\hline Dietary Habit (5) & $52.26 \pm 6.57$ & $47.77 \pm 6.32$ & $4.61^{* *}$ & $49.88 \pm 8.67$ & $49.07 \pm 6.08$ & 0.80 \\
\hline Rest Habit (6) & $55.64 \pm 7.95$ & $50.37 \pm 6.89$ & $4.67^{* *}$ & $52.06 \pm 8.29$ & $49.54 \pm 6.77$ & $2.45^{*}$ \\
\hline Life Habit (4) - (6) & $142.20 \pm 17.68$ & $127.86 \pm 16.01$ & $5.60^{* *}$ & $134.89 \pm 18.17$ & $126.74 \pm 15.67$ & $3.53^{* *}$ \\
\hline
\end{tabular}

${ }^{*} P<0.05,{ }^{* *} P<0.01$.

\section{Conclusion}

In this study, we compared people who regularly exercised and those who did not. It is useful to provide information for developing PE program. Moreover, PE programs are a required subject for the first year freshman. Therefore, we can attempt to increase health status and improve life habit in PE lessons. We hope our research can contribute to the work of physical education in China. Finally, the limitations of the study-the present study showed the small sample size, therefore, we should do examination for additional sample in future.

\section{References}

Kiuchi, A., Arai, H., Urai, R., \& Nakamura, T. (2009) Effects of Behavioral Science-Based Physical Education Program on the Physical Activity-Related Variable of College Freshmen: Project FYPE. Japanese Society of Physical Education, 54, 145-159. http://dx.doi.org/10.5432/jjpehss.a540115

Li, P., \& Wang, Y. (2007). A Study on Relationship between Lifestyle and Mental Health of College Students. The 12th East Asia Sports Exercise Science Society Annual Conference Proceedings, Shanghai, August 2007, 12-22.

Mao, Z (2009). View for Physical Education and Health Education. Beijing: The Publish of Beijing Physical Education University.

Ma, H. X., Yang, H. L., \& Wang, M. (2009). Physical Education and Health Status in University. China: Aero Industry Publication Company.

Sato, Y., Saito, S., \& Kamioka, H. (1996) The Relationship between Mental Health Status and Lifestyle in the Varsity Students. The Centre for Health and Sports Science, Gakushuin University, 9-30.

Tokunaga, K., \& Hashimoto, K. (2001). Development of Health and Life Habit Inventory for Students. Journal of Health Science, Kyushu University, 23, 53-63.

Tokunaga, K., \& Hashimoto, K. (2002). Effects of Life Habits of Young People on Their Health Levels Assessed. Journal of Health Science, Kyushu University, 24, 39-46.

Tokunaga, K. (2003). Diagnostic Inventory of Health and Life Habit (DIHAL.2) Scale. Fukuoka: Toyo Physical Corporation.

Wang, X. L. (2009). Research for Health Status /Lifestyle and the Expectation through the PE Lessons of College Students in China. Master Thesis, Japan: Graduate School of Human Environment Studies, Kyushu University.

WHO (World Health Organization) (2009). Basic Documents (47th ed.). http://apps.who.int/gb/bd/PDF/bd47/EN/basic-documents-47-en.pdf

Wang, X. L., \& Sugiyama, Y. (2011) Current Situation and Issues of University Physical Education in China. Journal of Health Science, Kyushu University, 33, 13-19.

Wang, X. L., \& Sugiyama, Y. (2014) Relationship between the Change in Health Status and Satisfaction with Physical Education in Chinese college students. Advance in Physical Education. 